\title{
CMR-based assessment of myocardial edema in the setting of ischemia and reperfusion
}

\author{
Avinash Kali ${ }^{1,2^{*}}$, Andreas Kumar ${ }^{3}$, Richard L Tang ${ }^{1}$, Rohan Dharmakumar ${ }^{1}$ \\ From 16th Annual SCMR Scientific Sessions \\ San Francisco, CA, USA. 31 January - 3 February 2013
}

\section{Background}

Cardiovascular Magnetic Resonance (CMR) based assessments of area-at-risk and salvageable myocardium on the basis of myocardial edema in the setting of acute coronary syndrome is of significant clinical interest. However, their dependence on the choice of acquisition method and time to imaging has not been studied. In this study, we investigated the temporal evolution of myocardial

edema during ischemia and reperfusion phases using both T2 maps and T2-STIR images.

\section{Methods}

Canines $(\mathrm{n}=10)$, subjected to I- $\mathrm{R}$ injury, underwent CMR (1.5T) before ischemia (baseline), during ischemia and on days 2, 5, and 7 post-reperfusion. T2-preapred SSFP (T2-preparation durations $=0,24$ and $55 \mathrm{~ms}$; TR/TE $=$

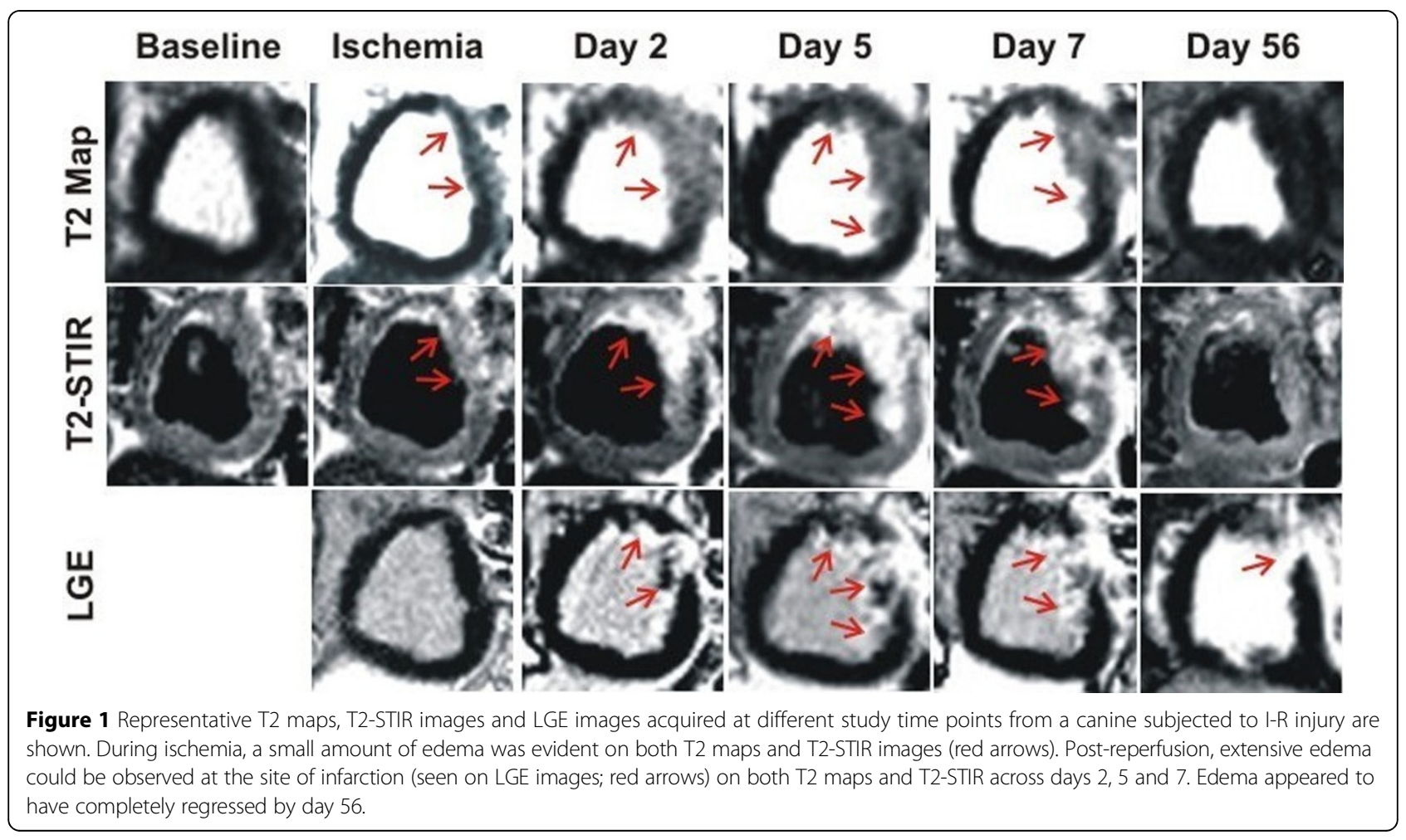

'Biomedical Imaging Research Institute, Cedars-Sinai Medical Center, Los Angeles, CA, USA

Full list of author information is available at the end of the article 

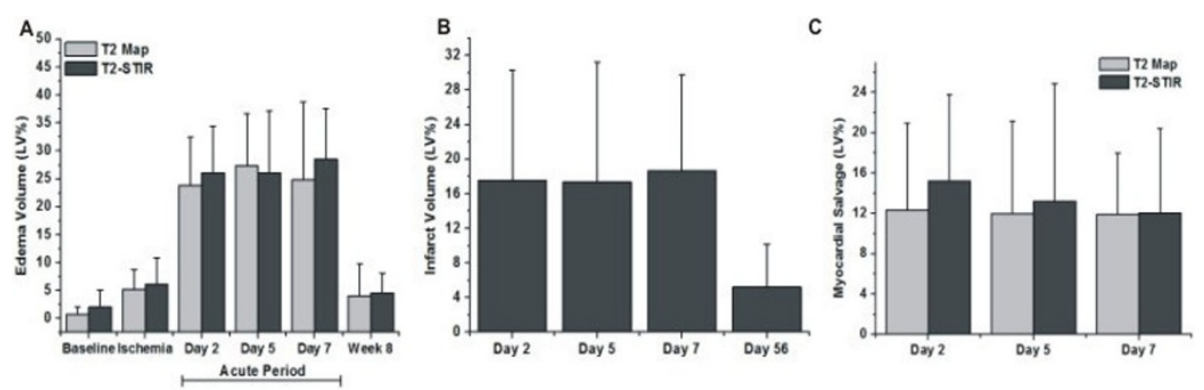

Figure 2 Mean percentage edema (A), infarct (B) and salvageable (C) volumes averaged across all the studies are shown at different time points. During ischemia, there was a small but significant amount of edema relative to baseline $(p=0.04)$. Following reperfusion, edema volume increased nearly 5 -fold across days 2, 5 and 7 ( $p<0.001$ ). Percentage edema, infarct and salvageable volumes remained constant across days 2,5 and 7 (Edema: $p=0.78$, Infarct: $p=0.21$, Salvageable: $p=0.72$ ). Percentage edema and infarct volumes returned to baseline levels by day 56 ( $p<0.001$ for both cases). Percentage edema volume during ischemia was significantly lower than both post-reperfusion percentage edema and infarct volumes ( $p<0.001)$. There was no difference between percentage edema and salvageable volumes computed by T2 maps and T2-STIR images at any time point.

2.2/1.1ms; BW = $1002 \mathrm{~Hz} /$ pixel), T2-STIR (TR = 2-3 RR intervals; $\mathrm{TE}=64 \mathrm{~ms} ; \mathrm{TI}=170 \mathrm{~ms} ; \mathrm{BW}=355 \mathrm{~Hz} /$ pixel $)$ and Late Gadolinium Enhancement (LGE; IR-prepared SSFP; TR/TE $=3.5 / 1.75 \mathrm{~ms}$; BW $=1002 \mathrm{~Hz} /$ pixel) images of the whole LV were acquired. T2 maps were constructed from T2-prepared SSFP images. Using threshold-based analysis, percentage edema volume (\%Edema from both T2 maps and T2-STIR images), infarct volume (\% Infarct from LGE images) and salvageable volume $(\%$ Salvage $=\%$ Edema $-\%$ Infarct $)$ were computed relative to total LV myocardial volume.

\section{Results}

Representative T2 maps, T2-STIR images and LGE images acquired from a canine at different study points are shown in Figure 1. During ischemia, there was a small but significant increase in \%Edema relative to baseline $(\mathrm{p}=0.04$; Figure 2A). Post-reperfusion, \%Edema was elevated nearly 5 -fold on days 2, 5 and 7 ( $\mathrm{p}<0.001$ for all cases). However, $\%$ Edema was constant across days 2,5 and $7(\mathrm{p}=0.78)$ and returned to baseline levels by day $56(\mathrm{p}=0.02)$. Both $\%$ Infarct and \%Salvage remained unchanged across days 2 , 5 and 7 ( $\mathrm{p}=0.21$ and 0.72 respectively; Figures $2 \mathrm{~B}$ and $2 \mathrm{C}$ ). Estimates of \%Edema during ischemia were significantly smaller than the post-reperfusion estimates of $\%$ Edema or \%Infarct ( $\mathrm{p}<0.001$ for both cases). Estimates of $\%$ Edema or \%Salvage obtained at any time point with T2 maps and T2-STIR images were not different $(\mathrm{p}=0.08$ and 0.74 respectively).

\section{Conclusions}

Although ischemia led to a small but significant increase in relative myocardial edema volume, it was not indicative of post-reperfusion infarct or edema volumes. Both relative edema and salvageable myocardial volumes remained unchanged during the sub-acute period of reperfused myocardial infarction. T2 maps and T2-STIR images provided equivalent information regarding relative edema and salvageable volumes.

\section{Funding}

This work was supported in part by grants from American Heart Association (SDG 0735099N) and National Heart, Lung, And Blood Institute (HL091989).

\section{Author details}

${ }^{1}$ Biomedical Imaging Research Institute, Cedars-Sinai Medical Center, Los Angeles, CA, USA. ${ }^{2}$ Department of Biomedical Engineering, University of California, Los Angeles, CA, USA. ${ }^{3}$ Quebec Heart \& Lung Institute, Laval University, Quebec City, QC, Canada.

Published: 30 January 2013

doi:10.1186/1532-429X-15-S1-P212

Cite this article as: Kali et al: CMR-based assessment of myocardial edema in the setting of ischemia and reperfusion. Journal of Cardiovascular Magnetic Resonance 2013 15(Suppl 1):P212.

\section{Submit your next manuscript to BioMed Central} and take full advantage of:

- Convenient online submission

- Thorough peer review

- No space constraints or color figure charges

- Immediate publication on acceptance

- Inclusion in PubMed, CAS, Scopus and Google Scholar

- Research which is freely available for redistribution 